\title{
Exploring potentials of digital nudging for business processes
}

\author{
Sandra Bammert, Research Center Finance \& Information Management, University of Augsburg \\ Ulrich Matthias König, Research Center Finance \& Information Management, Project Group Business \& \\ Information Systems Engineering of the Fraunhofer FIT, University of Augsburg \\ Maximilian Röglinger, Research Center Finance \& Information Management, Project Group Business \& \\ Information Systems Engineering of the Fraunhofer FIT, University of Bayreuth
}

Tabitha Marie Wruck, Research Center Finance \& Information Management, University of Augsburg

accepted 3 January 2020

This is a post-peer-review, pre-copyedit version of an article published in: Business Process Management Journal. The final authenticated version is available online at: https://dx.doi.org/10.1108/BPMJ-07-2019-0281

\begin{abstract}
Purpose - Business process improvement is vital for organizations as business environments are becoming ever more volatile, uncertain, complex, and ambiguous. Process improvement methods help organizations sustain competitiveness. Many existing methods, however, do not fit emerging business environments as they entail initiatives with long implementation times, high investments, and limited involvement of process participants. What is needed are agile process improvement approaches. The purpose of this paper is to explore the potential of digital nudging - a concept offering tools that lead individuals to better decisions - to improve business processes.
\end{abstract}

Design/methodology/approach - Using process deviance as theoretical lens, an online experiment with 473 participants is conducted. Within the experiment, business processes and digital nudges are implemented to examine whether digital nudging can mitigate the weaknesses of existing process improvement methods.

Findings - Digital nudging can influence the decisions of process participants and entail positive process deviance that leads to process improvement opportunities. Further, our research gives a first hint on the effectiveness of different digital nudges and lays the foundation for future research.

Research limitations/implications - Since exploring a completely new field of research and conducting the experiment in a synthetic environment, the paper serves as a first step towards the combination of digital nudging, business process improvement, and positive process deviance.

Originality/value - The major achievement reported in this paper is the exploration of a new field of research. Thus, digital nudging shapes up as a promising foundation for agile process improvement, a discovery calling for future research at the intersection of digital nudging and business process management.

Keywords Business Process Improvement, Process Deviance, Digital Nudging, Online Experiment.

Paper type Research paper 


\section{Introduction}

A common way to enhance an organization's products and services is to improve the underlying business processes (Dumas et al., 2018). Hence, one overarching goal of Business Process Management (BPM) is to improve business processes, with business process improvement (BPI) being considered as the most value-adding phase of the BPM lifecycle (van der Aalst et al., 2016; Dumas et al., 2018). If BPI methods are used appropriately, organizations can remain competitive and create sustained value (Kohlbacher and Reijers, 2013; Dumas et al., 2018;). In the last decades, a mature BPI toolbox has emerged (Harmon, 2018; Andrade et al., 2016), including approaches such as Total Quality Management (Walton, 1988), Lean Management (Chen and Taylor, 2009), Six Sigma (van der Aalst et al., 2016), and Business Process Reengineering (Al-Mashari et al., 2001). These methods aim for reduced time and cost as well as for enhanced quality (Reijers and Mansar, 2005; van der Aalst et al., 2016; Harmon, 2019) and flexibility (Reijers and Mansar, 2005). Furthermore, some BPI methods call for continuous process improvement, while others strive for radical change.

Nowadays, organizations are facing challenges in their business environments such as volatility, uncertainty, complexity, and ambiguity (Bennett and Lemoine, 2014). Consequently, process managers must handle the complexity of emerging inter- and intra-organizational process networks (Yusof and Aspinwall, 2000; Lehnert et al., 2016) as well as fast-changing and highly individual customer needs (Gimpel et al., 2018). Furthermore, they must ensure that envisioned process changes are eventually adopted by process participants. In many organizations, process participants tend to resist envisioned changes, a circumstance making it hard to improve processes successfully (Dumas et al., 2018). Many established BPI methods do not fit the characteristics of such business environments as they entail initiatives with long implementation times and limited involvement of process participants (Vakola and Rezgui, 2000; van der Aalst et al., 2016). Moreover, many process improvement projects lead to high investments (Buhl et al., 2011). Process managers can hardly anticipate the effects of process improvement projects (Vakola and Rezgui, 2000). To mitigate the weaknesses of existing BPI methods, existing BPI methods need to be complemented by more agile approaches (de Bruin and Rosemann, 2007; Kerpedzhiev et al., 2017; Satyal et al., 2019). One way to achieve this is to change the process execution environment - not the process itself - in order to influence the behavior of process participants.

Against this background, we see great potential in digital nudging to serve as foundation for agile process improvement, which can be faster and less obtrusive than existing approaches. Since Thaler's honoring with the Nobel Memorial Prize in Economic Sciences, nudging is a well-known concept in behavioral economics. It offers tools that lead individuals to better decisions through changes in their work environment (Weinmann et al., 2016). These changes, called nudges, can influence people's behavior and intention (Thaler and Sunstein, 2008). Digital nudging refers to nudging in digital or online environments (Weinmann et al., 2016; Mirsch et al., 2017). An example is the setting of defaults (i.e. preselecting options) in software installation processes (Mirsch et al., 2017). A key benefit of digital nudges is that they are cheaper and can be implemented faster than physical nudges (Mirsch et al., 2017). The effectiveness of nudging has already been shown in numerous studies (Thaler and Sunstein, 2008; John et al., 2013; Goldin, 2015) and contexts such as user interface design (Goldstein et al., 2008; Khern-amnuai et al., 2017; Pahuja and Tan, 2017), healthcare (Thaler and Sunstein, 2008; Noar et al., 2015), or sustainability (Demarque et al., 2015; Chang et al., 2016). Hence, we assume that nudging can also influence the behavior of process participants with positive effects on process performance. To the best of our knowledge, however, the potential of digital nudging for BPM in general and for BPI in particular, yet needs to be explored. With this study, we would like to take a first step to tackle this gap. Hence, our research question is: What is the potential of digital nudging for business process improvement?

To address this research question, we conducted an online experiment with 473 participants, two business processes taken from Andrade et al. (2016) whose proneness to positive deviance has already been shown, and five digital nudges (i.e. Incentive, Salience, Precommitment, Default Setting, and Additional Information) whose effectivity has already been confirmed in earlier studies (Ashraf et al., 2006; Goldstein et al., 2008; Houde et al., 2013; Pahuja and Tan, 2017; Schneider et al., 2018). Thereby, we chose positive deviance as analytical lens as Andrade et al. (2016) found that positive intentions of process 
participants can improve business processes and lead to superior performance. In the experiment, we analyzed if and with which intention process participants deviated from given processes by coding their qualitative feedback. On this foundation, we examined whether the digital nudges in focus stimulate positive deviance and, as such, have the potential to improve business processes. This paper contributes to existing knowledge in three ways: (i) we demonstrate the positive impact of digital nudging for BPM and BPI, (ii) we show that it is technically possible to use nudges in business processes and use them for nudging employees and not just customers, and (iii) we have successfully tested the use of various nudges in a process context.

The remainder of this paper is organized as follows: First, we provide theoretical background on BPM, $\mathrm{BPI}$, process deviance, and (digital) nudging to set the scene for the online experiment. We then present our research method including the experimental setup, followed by data analysis and results. Finally, we discuss theoretical as well as practical implications and examine limitations as well as opportunities for future research.

\section{Theoretical Background}

\subsection{Business Process Management and Process Deviance}

BPM is "the art and science of overseeing how work is performed in an organization to ensure consistent outcomes and to take advantage of improvement opportunities" (Dumas et al., 2018, p. 1). Over the years, BPM has evolved into a mature discipline with the primary goal of improving business processes (van der Aalst et al., 2016). Business processes encompass decision points, events, activities, tasks, actors, physical and immaterial objects which lead to valuable outcomes for customers (Dumas et al., 2018). In addition, BPM is typically structured by taking a lifecycle perspective, including phases such as the identification, modelling, analysis, improvement, implementation, monitoring and controlling of business processes (Dumas et al., 2018).

However, emerging technologies, such as artificial intelligence (Koehler, 2018), require to re-conceptualize BPM in order to enable efficient and competitive work in the digital age (Kerpedzhiev et al., 2017). A starting point is the adoption of frameworks such as maturity models and thus, the assessment of new capabilities and their influence on processes (Ferraris et al., 2017). Such models are a common basis to evaluate business processes and their improvement potential (Harmon, 2004). One well-known BPM capability framework is that authored by de Bruin and Rosemann (2007) consisting of six factors (i.e. strategic alignment, governance, methods, information technology, people, and culture) as well as associated capability areas. Kerpedzhiev et al. (2017) further developed this framework and proposed that, in the digital age, BPM capabilities should be centred around six topics i.e. data, humans, opportunities, networks, context, and change. Specifically, they argue that BPI should support an agile and a transformational mode. Agile process improvement aims for the iterative improvement of business processes and the fast evaluation of novel process designs and improvement ideas based on real performance data and feedback from process participants (Martins and Zacarias, 2017).

Process deviance, which we use as analytical lens in our experiment to identify improvement opportunities, can occur in individual tasks, sub-processes, or entire processes (Dumas and Maggi, 2015; König et al., 2018). In general, processes can be classified as deviant in case their behavior significantly differs from the average or other expected values or from formal or informal norms such as process models (Kim et al., 2008; Seidman and McCauley, 2008). Moreover, deviance can occur intentionally or unintentionally (Depaire et al., 2013; Mertens et al., 2016; König et al., 2018), with this paper we put the focus on unintentional process deviance, as one opportunity to improve a process participants' intention. Process deviance can have positive (constructive) and negative (detrimental) effects on process performance, based on the underlying intention (Alter, 2014; Andrade et al., 2016; König et al., 2018). Negative intentions, e.g. lying or stealing, can harm organizations (Alter, 2014). An intention is seen as positive if it is perceived as positive by a reference group (Spreitzer and Sonenshein, 2004; Galperin, 2012), if it has a positive impact on the organization (Vadera et al., 2013), or if it positively affects corporate performance or success (Seidman and McCauley, 2008; Cohn, 2009; Pascale et al., 2010;). 
According to Mertens and Recker (2017), it is a common assumption that people positively deviate triggered by impulses, which are in most cases caused by elements from their surroundings, themselves, or the combination of both. Hence, positive intention can be seen as a "source of future improvements" (Alter, 2014, p. 1053) as it displays areas that can be changed and improved (Brady, 2003). Thus, positive deviance is an appropriate indicator pointing to improvement potential in frequently executed business processes. We use these findings about positive intentions to investigate whether digital nudging stimulates positive process deviance in order to explore its potential for BPI.

\subsection{Digital Nudging}

Thaler and Sunstein (2008) define nudging as a concept that aims to improve the decisions people make with neither changing the economic incentives nor forbidding or recommending any options directly. To apply nudging, the choice architecture has to be changed (Thaler and Sunstein, 2008). There are various possibilities how these changes, called nudges, could look like. Choice architectures, i.e. the environment in which decisions are made, are designed by choice architects. As they influence people's decisions, there is no neutral way to design or present choices (Thaler and Sunstein, 2008).

The underlying theory of nudging is called dual-processing, which is an established concept in psychology and examines how humans process information and make decisions (Evans, 2008). Dual-processing distinguishes between two modes how people process information: System I and System II. System I is unconscious, automatic, and needs low cognitive effort, whereas System II is conscious, controlled, analytic and high cognitive effort is needed. System I processes information fast and uses heuristics to make decisions (Evans, 2008). Heuristics are rules of thumb within choice architectures, reducing task complexity. Heuristics can lead to biases, i.e. systematic errors, like misjudging probabilities (Tversky and Kahnemann, 1974). Because of its fast processing characteristics, System I can be easily influenced by slight and unobtrusive changes in the choice architecture. This may lead to different decisions. System II instead processes information slowly based on analytic reasoning (Evans, 2008). The concept of nudging focuses on System I and can effectively change decisions and behavior (Dolan et al., 2012). Below, we focus on nudges and consider neither the underlying heuristics nor the resulting biases.

Digital nudging is a special form of nudging where nudges are used in digital work and online environments such as user interfaces (Weinmann et al., 2016; Mirsch et al., 2017). That is, digital nudges are facilitated through information technology (Gregor and Lee-Archer, 2016). Thus, user interfaces serve as choice architecture, which can be changed by choice architects to influence individuals' behavior. Many studies have evaluated whether nudges are beneficial in different contexts like health, finance, energy consumption, environment or policy making (Thaler and Sunstein, 2008; Dolan et al., 2012; Weinmann et al., 2016; Meske and Potthoff, 2017), and how the digital nudges can be developed and implemented (Mirsch et al., 2017; Gregor and Lee-Archer, 2016). The frequency of nudges used, varies greatly depending on the context and the difficulty of implementation (Hummel and Maedche, 2019). Since nudges vary a lot in their effectiveness (Hummel and Maedche, 2019), we discuss nudges whose effectiveness has already been shown in earlier studies (e.g. Ashraf et al., 2006; Goldstein et al., 2008; Houde et al., 2013; Pahuja and Tan, 2017; Schneider et al., 2018) and that seem to be commonly used in the literature. These nudges are Incentive, Salience, Precommitment, Default Setting, Additional Information, Social Norms, and Scarcity (Table 1). Incentive is one of the initial nudges described by Thaler and Sunstein (2008). The incentive is not an economic one, meaning that the financial/material situation is not changed. Instead, it shows the consequences of the decisions made (Hansen and Jespersen, 2013). Behavioral studies show that cognitive resources are restricted and that humans mainly focus on easily accessible, salient information (Mann and Ward, 2007). As one would expect, this leads to different decisions, based on the Salience of information. The Precommitment strategy nudges people to engage in a certain behavior or action, e.g. in the form of signing a contract that specifies exercise goals (Dolan et al., 2012). Precommitment makes it easier to stick to their goals. Another very common nudge - Default Setting - uses individuals' tendency to stick to the status quo and to overrate the disadvantages of changing anything (Mirsch et al., 2017). Studies found that the decisions individuals made were improved through offering Additional Information (Schneider et al., 2017). Social Norms leverages 
group rules to influence people within the same social group to stick with these norms (Mirsch et al., 2017). Croson and Shang (2008) showed that people tend to adapt the amount they donate when they are presented with social norms. When they are told that most people donate less than them, they also donate less and the other way around. Finally, Scarcity is based on people's tendency to prefer scarce objects such that it is more likely that scarce objects are preferred over abundant ones (Schneider et al., 2018). Nudges have been proven to influence the decisions people make by influencing System I. On this foundation, we consider digital nudges in business processes through positive process deviance.

\begin{tabular}{|l|l|l|}
\hline Nudge & Description & Studies showing effectiveness \\
\hline Incentive & $\begin{array}{l}\text { Showing consequences of the decisions made } \\
\text { (Hansen and Jespersen, 2013) }\end{array}$ & $\begin{array}{l}\text { Houde } \text { et al. } \text { (2013); Noar } \text { et al. } \\
(2015)\end{array}$ \\
\hline Salience & $\begin{array}{l}\text { Designing important information more promi- } \\
\text { nent (Mann and Ward, 2007) }\end{array}$ & $\begin{array}{l}\text { Chetty } \text { et al. } \text { (2009); Pahuja and Tan } \\
(2017)\end{array}$ \\
\hline Precommitment & $\begin{array}{l}\text { Getting the precommitment of people to en- } \\
\text { gage in a certain behavior (Dolan } \text { et al., 2012) }\end{array}$ & Ashraf et al. (2006) \\
\hline Default Setting & $\begin{array}{l}\text { Using default settings to remain with the status } \\
\text { quo (Mirsch } \text { et al., 2017) }\end{array}$ & $\begin{array}{l}\text { Halpern et al. (2007); Goldstein et } \\
\text { al. (2008) }\end{array}$ \\
\hline $\begin{array}{l}\text { Additional } \\
\text { Information }\end{array}$ & $\begin{array}{l}\text { Offering additional information to improve de- } \\
\text { cisions (Schneider } \text { et al., 2017) }\end{array}$ & $\begin{array}{l}\text { Khern-am-nuai et al. (2017); Schnei- } \\
\text { der et al. (2017) }\end{array}$ \\
\hline Social Norms & $\begin{array}{l}\text { Providing information about rules and stand- } \\
\text { ards of a group (Mirsch } \text { et al., 2017) }\end{array}$ & $\begin{array}{l}\text { Croson and Shang (2008); Bond et } \\
\text { al. (2012) }\end{array}$ \\
\hline Scarcity & $\begin{array}{l}\text { Pretending a choice option to be scarce (Mirsch } \\
\text { et al., 2017) }\end{array}$ & Schneider at al. (2018) \\
\hline
\end{tabular}

\section{Research Method}

To answer our research question, we conducted an online experiment based on two business processes that have already been proven to be prone to positive deviance (Andrade et al., 2016). The participants were assigned to one experimental group each implementing one of five nudges or to the control group without a nudge. The participants provided qualitative feedback that was coded by the authors independently. The feedback was evaluated to examine whether the participants intended to deviate positively from the processes. Afterwards, the digital nudges in focus have been analyzed regarding their effects on positive deviance. We decided to use a "black box testing" approach to assess whether nudges can lead to positive process deviance. Hence, our experiment is positioned as non-hypothetical, descriptive, and causation-demonstrating (Andersson, 2012). We chose this type of experiment, as we explore the intersection of two research fields where no proper theory base is available for answering our research question.

\subsection{Experiment Design}

As described in Section 2.2, we selected nudges whose effectiveness has already been proven in different studies (Ashraf et al., 2006; Goldstein et al., 2008; Houde et al., 2013; Pahuja and Tan, 2017; Schneider et al., 2018). To select digital nudges for the purposes of our experiment, we identified common digital nudges by analyzing how often they are mentioned in the literature. We then selected those nudges that could fit a business process context by analyzing their characteristics. The digital nudges should fit different processes, especially to the process activities where we want to implement nudges. Scarcity, for example, needs a possibility to simulate a limitation, which is not possible for business processes in general. Hence, one of the nudges we could not use in our experiment was Scarcity. After this preselection of digital nudges, we discussed the remaining digital nudges with a focus group to find out, which nudges would fit our experimental setting best. The focus group consisted of ten participants who were 
either master students with a major in BPM, $\mathrm{PhD}$ students or professors from the BPM domain. We presented the digital nudges and explained our approach to stimulate positive deviance in business processes. After that, we agreed to use the five digital nudges Incentive, Salience, Precommitment, Default Setting, and Additional Information.

Although we created a synthetic environment for our experiment, we looked for elements to make the setting as realistic as possible. Therefore, we looked for well-accepted business processes, which are easily understandable without further domain-knowledge. An additional and useful prerequisite was to ensure the possibility of positive deviance. Hence, we selected two business processes described by Andrade et al. (2016) which seemed to fit these criteria. Andrade et al. (2016) conducted a case study in the customer service department of a German IT company, hosting a leading online project platform. They demonstrated that it is possible to positively deviate from these processes and that especially "wellintended noncompliance has mostly positive effects" (Andrade et al., 2016, p. 7). In our experiment, we analyzed both business processes independently.

The Account Deletion process (ADP) is triggered by a user's request to delete the account. The customer support needs to check whether the user has open invoices and to ask the customer to pay them if this is the case. As soon as all invoices are paid, the customer support deletes the account (Figure 1) (Andrade et al., 2016). The Technical Request process (TRP) is also triggered by a customer inquiry informing the department about a technical problem (e.g. issues with opening the website). If the problem is known and a solution is available in the record, the customer is informed about necessary steps to solve the problem, if possible. If there is no solution available, the technical department is informed about the problem. When the technical department provides a problem solution, the customer is contacted (Figure 2) (Andrade et al., 2016). Andrade et al. (2016) described various possibilities to deviate from these business processes, e.g. by "Asking why customer wants to delete account", "Performing task on behalf of customer", or "Calling customer instead of writing an e-mail".

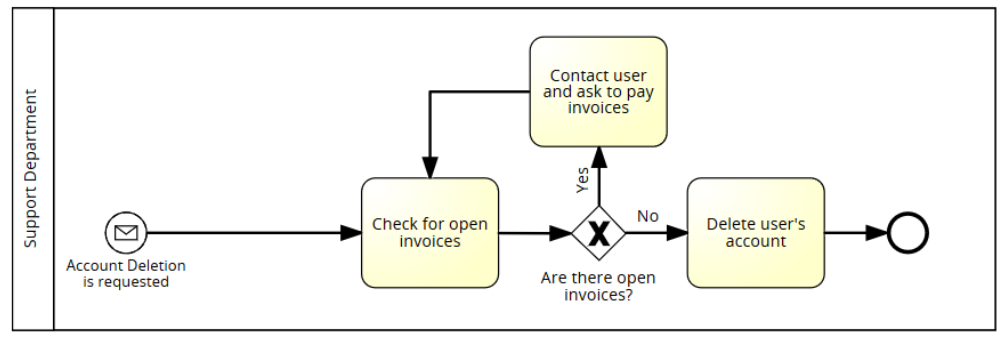

Figure 1. Account Deletion Process (ADP)

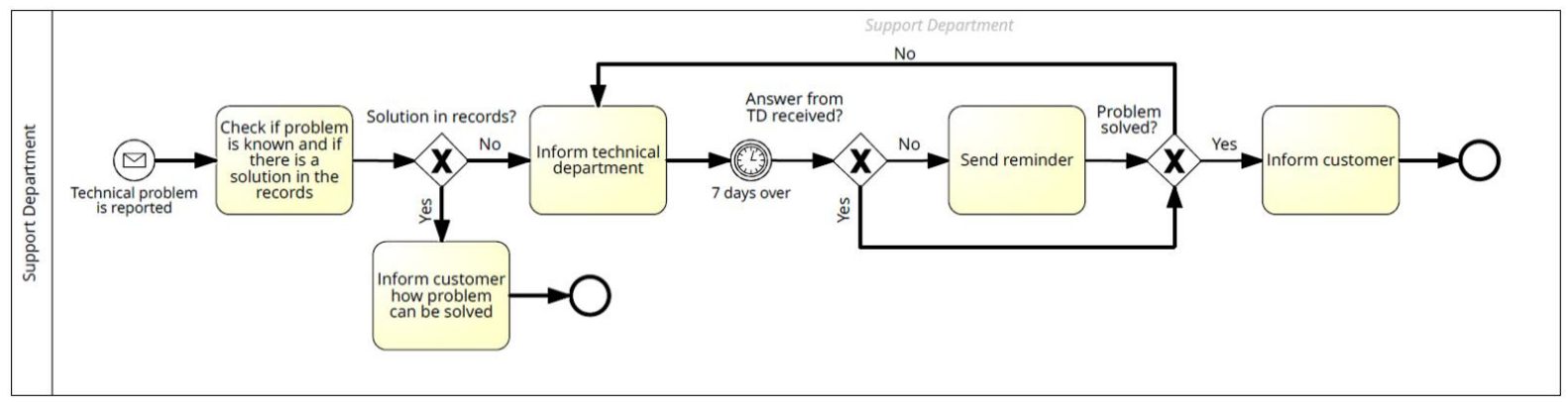

Figure 2. $\quad$ Technical Request Process (TRP)

\subsection{Experimental Setup}

In the experiment, participants were randomly assigned to one of the two business processes and either to the control group or one of the five experimental groups. In the control group, no nudge was implemented. This leads to 12 different groups. Thus, we could eliminate dependencies between processes 
and nudges. The processes were implemented in an online survey tool and we used free text fields such that participants could describe their actions and thoughts. The online experiment was implemented in English and German. Both versions were approved by a native speaker. Additionally, prior to the main experiment, we conducted a qualitative pre-test with six participants, $\mathrm{PhD}$ and master students with a major background in BPM, to ensure that the experimental instructions were understandable. We conducted three rounds of face-to-face pre-tests with two participants per round. After each round, the feedback was discussed and implemented.

Technically, both business processes and the digital nudges were implemented the same way. As shown in Table 2, the participants first had to select the communication channel (ADP) or the person they want to contact (TRP) from a checkbox list. Afterwards, they had to provide reasons for their decision and to write down what they would have liked to tell the customer. Participants also had the opportunity to comment on the process. The ADP was finished after that activity, while the TRP led the participants to an optional site, where they had to write down what they would tell the technical department, if this had not been chosen before. The participants continued to explain what the content of their message would be and if they had any optional comments about the process.

\begin{tabular}{|c|c|c|c|}
\hline Type & Activity & Account Deletion Process (ADP) & Technical Request Process (TRP) \\
\hline List & 1 & $\begin{array}{l}\text { Decision how to contact the customer: } \\
\text { - E-mail } \\
\text { - Phone } \\
\text { - Mail/Fax }\end{array}$ & $\begin{array}{l}\text { Decision whom to contact: } \\
\text { - } \text { Customer } \\
\text { - Supervisor } \\
\text { - } \\
\text { - } \\
\text { Technical Deportment }\end{array}$ \\
\hline \multirow{6}{*}{$\begin{array}{l}\text { Free text } \\
\text { field }\end{array}$} & 2 & Reasoning for communication channel & Reasoning for contacted person \\
\hline & 3 & Content of what to tell the customer & Content of what to tell the chosen person \\
\hline & 4 & Option to comment the process & Option to comment the process \\
\hline & 5 & & $\begin{array}{l}\text { Content of what to tell the technical de- } \\
\text { partment (if not chosen earlier) }\end{array}$ \\
\hline & 6 & & Content of what to tell the customer \\
\hline & 7 & & Option to comment the process \\
\hline
\end{tabular}

Table 2. $\quad$ Process activities within the experiment

The control group was led through the process as described, whereas the experimental groups were presented with one of five digital nudges. The Incentive and the Salience groups received information about the financial consequences of losing a customer (ADP) or that customers can easily get annoyed if they receive no feedback on an inquiry or if it takes too long to solve their problems (TRP). This notification was provided unobtrusively in text form (Incentive) or in an eye-catching manner through a detached notification box (Salience). Figure 3 exemplary shows the actual presentation of the nudge Salience (ADP) in our experimental design. The Precommitment group had to agree with an internal policy, i.e. to provide customers with solutions, make confident decisions, and act in a way that increases the organization's profit. The Default Setting group had to actively decide against e-mailing the customer (ADP) or to contact the technical department (TRP) which were selected in advance, because they comply with the intended form of the business processes. The Additional Information group received a more detailed description of the process and saw the Business Process Model and Notation (BPMN) process model shown in Section 3.1.

Resulting from the different process activities, the participants had two (ADP) respectively three or four (TRP) possibilities to deviate from the processes, depending on their choices made throughout the execution. During the ADP they could deviate by not choosing e-mail as communication channel (activity 1) and by not (only) asking the customer to pay the open invoices (activity 3 ). During the TRP the participants could deviate by not choosing the technical department (activity 1) and not (only) asking to 
fix the problem if the technical department is chosen (activity 3 or 5) and differing in the content of communicating with the customer (activity 6).

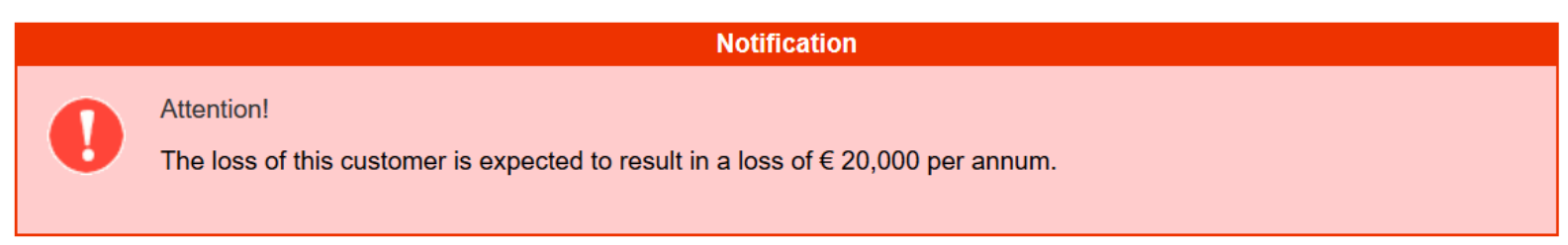

Figure 3. Actual presentation of the nudge Incentive (ADP)

\subsection{Data Collection}

We started the main experiment in October 2018. To that end, we recruited 269 participants from different survey-sharing platforms as well as from various universities and private networks. Another 250 participants holding a master qualification were recruited from Amazon Mechanical Turk, an online marketplace for business services. We required the master qualification to ensure that the workers are performing consistently well and to receive high data quality (Peer et al., 2014). The participants received a monetary compensation of $\$ 0.95$ for participating in the experiment. Earlier research has demonstrated that the usage of Amazon Mechanical Turk is reliable and provides a more diverse pool of participants compared to classical survey-sharing platforms (Behrend et al., 2011; Buhrmester et al., 2011). After excluding all unanalyzable feedbacks, we had the feedback of 473 participants in total.

\subsection{Coding}

The participants' qualitative feedback extracted from the free text fields was coded independently by the authors. We conducted the coding as part of the content analysis suggested by Krippendorff (2004) to guarantee that our results are reliable, replicable, and valid. During the coding, individuals - here: the authors - interpret the provided data according to observer-independent rules (Krippendorff, 2004). Hence, we developed coding instructions based on the feedback of the first 100 participants to determine which type of feedback leads to either positive, negative, or no process deviance (or not assessible / n.a.).

We divided the answers into two parts to analyze process deviance: the way of communication and the content of communication. In the ADP, the first opportunity for deviance is the answer and justification on how process participants would communicate with the customer (activities 1 and 2 in Table 2), the second opportunity is about the content of the answer they would have sent (activities 3 and 4 in Table 2). Regarding the TRP, the first step was the answer and justification on who they wanted to communicate with (activities 1 and 2 in Table 2) and the second was about the content of all messages they would have sent (activities 3 to 7 in Table 2). For each part, we chose if there was a deviation and whether the intention of the deviation was negative (neg), positive (pos), or not assessible (n.a.). The intention was categorized as positive if a participant wanted to increase customer loyalty and offer high-quality service. For a better understanding we propose the following detailed example: In that example is a participant assigned to the ADP with Incentive as nudge implemented and the first decision is about how to contact the customer in order to ask for the outstanding payments. The participant chose the option to contact the customer by phone not using the options e-mail, mail, or fax. We detected that as deviation from the standard process as contacting via e-mail is the standard. Afterwards, we analyzed the reasons the participants mentioned in the second activity. In our example, the participant wanted to get better feedback from the customer. Therefore, we determined the "way of communication"-related deviation as positive. Other often called explanation were "to get faster and better feedback from the customer", "personal closeness", or "better clarification of misunderstandings",

The intention was categorized as negative if a participant wanted to avoid work or if their reaction was out of scale (e.g. threaten with consequences). Not assessible was only chosen if a participant deviated 
from the prescribed process, but the intention was not clearly recognizable. On this foundation, we determined the overall deviance per participant: if the deviation in both parts matched, the overall deviance was chosen accordingly. If one part was n.a. or none, the overall deviance was chosen in line with explicit part. Otherwise, we discussed the overall intention in the coding team and decided based on the provided rationale (Table 3 ).

\begin{tabular}{|c|c|c|c|c|c|}
\hline \multicolumn{2}{|c|}{} & \multicolumn{4}{|c|}{ "Way of communication"-related Deviance } \\
\cline { 3 - 6 } \multicolumn{2}{|c|}{} & Positive & Negative & n.a. & None \\
\hline \multirow{3}{*}{$\begin{array}{c}\text { content of } \\
\begin{array}{c}\text { communica- } \\
\text { tion"-related } \\
\text { Deviance }\end{array}\end{array}$} & Positive & Positive & Discussed & Positive & Positive \\
\cline { 2 - 6 } & Negative & Discussed & Negative & Negative & Negative \\
\cline { 2 - 6 } & None & Positive & Negative & n.a. & n.a. \\
\cline { 2 - 6 } & Positive & Negative & n.a. & None \\
\hline
\end{tabular}

Table 3.

Coding guidelines for determining the overall deviance result

After the coding, we performed an inter-rater reliability (IRR) analysis to assess the extent to which the coders consistently evaluated the type of deviance according to Table 3. To that end, we chose Cohen's (1960) kappa as a common measure for nominal variables:

$$
k=\frac{\mathrm{P}(\mathrm{a})-\mathrm{P}(\mathrm{e})}{1-\mathrm{P}(\mathrm{e})}
$$

$\mathrm{P}(\mathrm{a})$ denotes the observed percentage of agreement between two coders, and $\mathrm{P}(\mathrm{e})$ denotes the probability of expected agreement due to chance. Kappa $k$ has a value range from -1 to 1 , with 1 indicating perfect agreement, 0 indicating random agreement, and -1 indicating perfect disagreement (Hallgren, 2012).

\begin{tabular}{|c|c|c|c||c|}
\hline \multicolumn{2}{|c|}{} & \multicolumn{2}{c||}{ Coder A } & \multirow{2}{*}{ Total } \\
\cline { 3 - 4 } \multicolumn{2}{c|}{} & Neg./None/n.a. & Positive & ./None \\
\hline \multirow{2}{*}{ Coder B } & Neg./No. & 44 & 9 & 53 \\
\cline { 2 - 4 } & Positive & 1 & 51 & 52 \\
\hline \hline \multicolumn{2}{|c|}{ Total } & 45 & 60 & 105 \\
\hline
\end{tabular}

Table $4 . \quad$ Exemplary agreement matrix

$\mathrm{P}(\mathrm{a})$ is indicated by the sum of the diagonal values divided by the total number of subjects, $(44+51) / 105$ $=0.905$. Coder A rated process deviance as positive 60/105 $=0.57$ times while Coder B rated it $53 / 105=0.50$ times. The probability of obtaining agreement about positive deviance is if ratings were assigned randomly between coders would be $0.57 \times 0.50=0.285$, and the probability of obtaining chance agreement about non-positive process would be $(1-0.57) \times(1-0.50)=0.215$. The total probability of any chance agreement $(\mathrm{P}(\mathrm{e}))$ would then be $0.285+0.215=0.50$, and $\kappa=(0.905-0.50) /(1-0.50)=0.81$.

We computed Cohen's kappa twice to compare the initial agreement (before discussing the first 100 questionnaires) and the agreement of the coders after developing coding instructions. As mentioned, three coders first rated the type of deviance for the first 100 participants. For three or more coders, Cohen's kappa needs to be adjusted meaning that Kappa was computed for each coder pair and then averaged (Light, 1971). In the second step, two coders independently evaluated the feedback of the remaining participants in line with jointly developed coding instructions.

\subsection{Statistical Tests}

Finally, we performed a chi-square $\left(\chi^{2}\right)$ test which is often used in experimental settings where data is analyzed in terms of frequencies. It is a nonparametric statistical method used to assess the probability of association or independence (Mendenhall and Beaver, 2013). In our case, the $\chi^{2}$ test for two dimensions was conducted to test whether the two groups are independent. This test can be applied to two dichotomous and nominally scaled characteristics (Rasch et al., 2010). For each computation, we created a $2 \times 2$ matrix that consisted of the two variables positive and non-positive (i.e. the sum of negative, none, 
and n.a. assessments) and two groups, the control group and one experimental group. This was done for both processes. If an association was detected, its intensity was measured by computing the squared phi coefficient $\left(\phi^{2}\right)$ for each pair which is equal to $w^{2}$, the coefficient for the general $\chi^{2}$-test (Rasch et al., 2010).

\section{Results}

After consolidating all questionnaires received, we had 473 participants in total and at least 34 participants per group. The age of the participants ranged from 19 to 72 years with an average age of 33 years. Within the participants, we were able to ask $53.91 \%$ females, $44.40 \%$ Germans as well as $39.96 \%$ US Americans. Moreover, we had a majority of $65.33 \%$ that are currently employed and $30.87 \%$ that are currently studying. In addition, $73.78 \%$ confirmed that they already had experience with customer contact or customer support, e.g. through their job or an internship. Table 5 summarizes the absolute numbers of participants across all groups. Although participants were equally likely assigned to the various groups and processes, there are differences owing to uneven dropout rates.

\begin{tabular}{|c|c|c|c|c|c|c||c|}
\hline & $\begin{array}{c}\text { Control } \\
\text { Group }\end{array}$ & Incentive & $\begin{array}{c}\text { Precommit- } \\
\text { ment }\end{array}$ & Salience & $\begin{array}{c}\text { Default } \\
\text { Setting }\end{array}$ & $\begin{array}{c}\text { Additional } \\
\text { Information }\end{array}$ & Total \\
\hline ADP & 34 & 45 & 40 & 38 & 47 & 38 & 242 \\
\hline TRP & 40 & 34 & 39 & 35 & 40 & 43 & 231 \\
\hline Total & 74 & 79 & 79 & 73 & 87 & 81 & 473 \\
\hline
\end{tabular}

Table $5 . \quad$ Number of participants per group

In the first coding step (first 100 participants), we achieved a kappa $k=0.76$ for both processes, which indicates substantial agreement according to Landis and Koch (1977). In the second coding step (remaining participants), we gained the same overall kappa. Hence, our results are highly reliable and valid as we met the requirements available in the literature and as we followed the coding instructions. The few remaining disagreements were discussed, leading to the descriptive results shown in the Figures 4 and 5. Both figures display how often we detected no deviance (none), positive as well as negative deviance, and not assessible (n.a.) deviations. In most cases, we detected no or positive deviance. Therefore, we focus on the comparison of positive deviance and no deviance in our further analysis (Table 6).

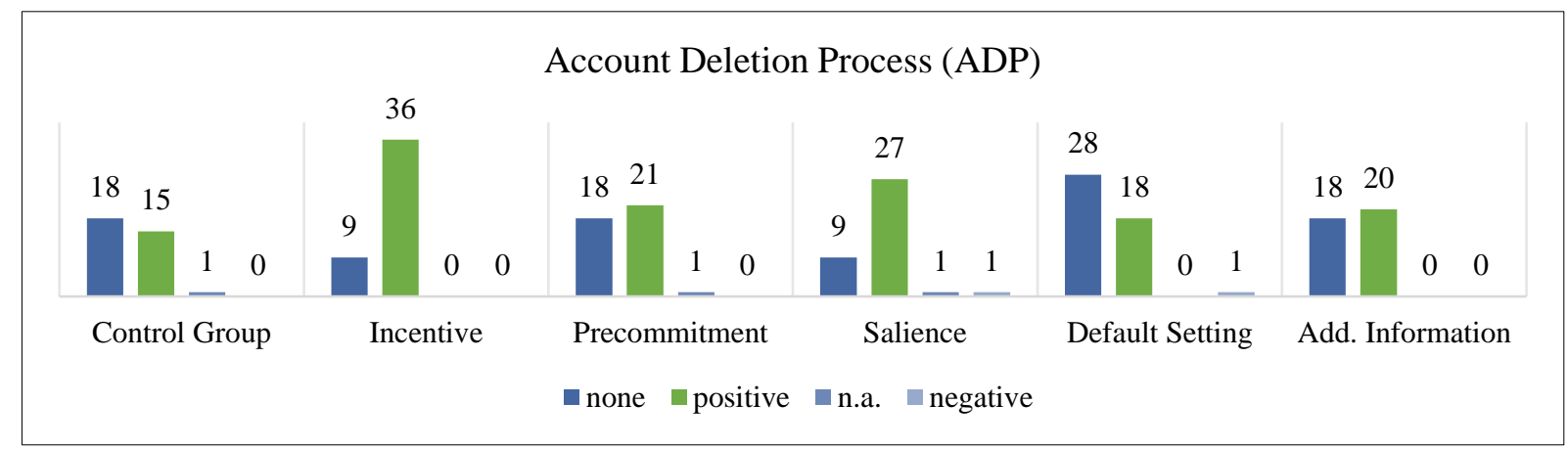

Figure 4. $\quad A D P$ - Deviance detected per group 


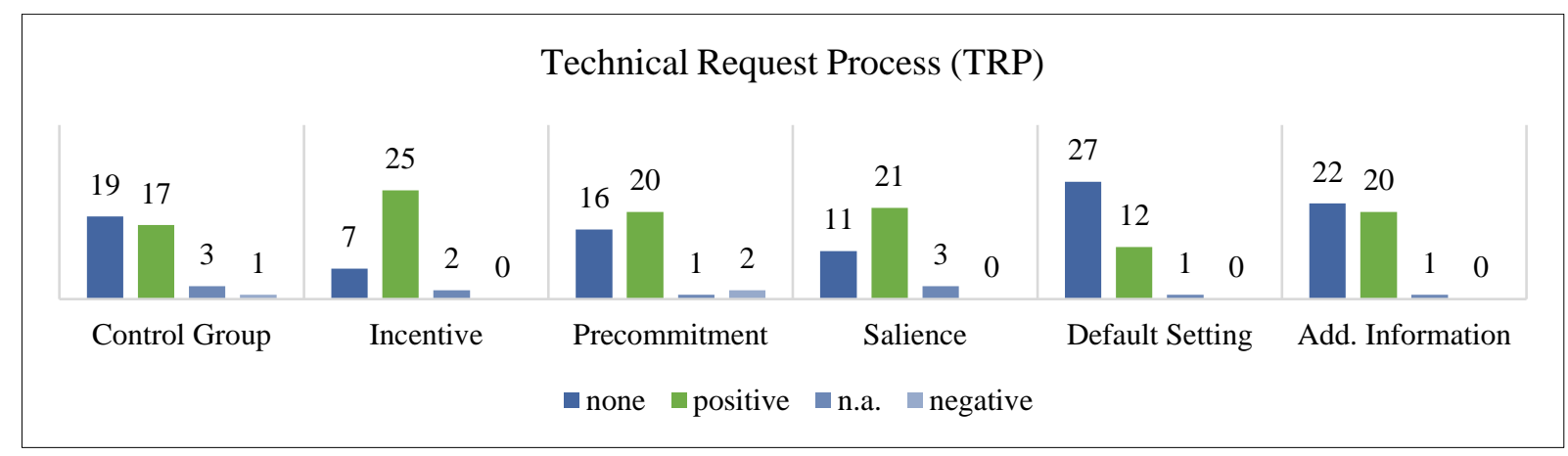

Figure 5. TRP - Deviance detected per group

\begin{tabular}{|c|c|c|c|c|c|c|}
\hline & $\begin{array}{c}\text { Control } \\
\text { Group }\end{array}$ & Incentive & $\begin{array}{c}\text { Precommit- } \\
\text { ment }\end{array}$ & Salience & $\begin{array}{c}\text { Default } \\
\text { Setting }\end{array}$ & $\begin{array}{c}\text { Additional } \\
\text { Information }\end{array}$ \\
\hline ADP & $44 \%$ & $80 \%$ & $53 \%$ & $71 \%$ & $38 \%$ & $53 \%$ \\
\hline TRP & $43 \%$ & $74 \%$ & $51 \%$ & $60 \%$ & $30 \%$ & $47 \%$ \\
\hline \hline Total & $43 \%$ & $77 \%$ & $52 \%$ & $66 \%$ & $34 \%$ & $49 \%$ \\
\hline
\end{tabular}

Table $6 . \quad$ Relative positive deviance detected per process and across the entire sample (total)

In both business processes, we observed tendency towards positive deviance, i.e. within each group the percentage of positive deviance detected is high/low for both processes at the same time. This finding indicates that similar conclusions can be drawn from the results of either the ADP or TRP. The highest number of positive deviance was observed within the experimental groups Incentive, $80 \%$ in ADP and $74 \%$ in TRP, and Salience with $71 \%$ in ADP and $60 \%$ in TRP. Both digital nudges seem to be the most effective ones altering the choice architecture, stimulating positively deviant behavior. The proportion of positive deviance detected in the control groups (43\%) was slightly lower than the related proportions in the groups Additional Information (49\%) and Precommitment (52\%). Surprisingly, this shows that without digital nudges almost half of the participants deviated positively. This finding may be rooted in various reasons, e.g. a high degree of answer options due to many free text areas and the participants' strong customer orientation. Further, the nudges Additional Information and Precommitment had a relatively small positive influence on the participants' behavior. Default Setting is an exception as only every third participant (34\%) positively deviated from the predefined process. This finding shows that a higher number of participants than those in the control group stuck to the process.

In a next step, we wanted to validate our results by focusing on those $74 \%$ of the participants who had confirmed that they already had experience with customer contact or customer support. The results from this analysis confirm the results of our first analysis, since we observed tendencies towards positive deviance in both processes at the same time. Relative positive deviance detected per process differs only slightly from the previous results, and there are almost no deviations when analyzing the whole sample, i.e. 349 of 473 participants. However, we could detect that there is a much higher percentage $(+8 \%$ points) within the group where we implemented the nudge Salience. This result even strengthens our finding mentioned before.

\begin{tabular}{|c|c|c|c|c|c|c|}
\hline & $\begin{array}{c}\text { Control } \\
\text { Group }\end{array}$ & Incentive & $\begin{array}{c}\text { Precommit- } \\
\text { ment }\end{array}$ & Salience & $\begin{array}{c}\text { Default } \\
\text { Setting }\end{array}$ & $\begin{array}{c}\text { Additional } \\
\text { Information }\end{array}$ \\
\hline ADP & $50 \%$ & $77 \%$ & $52 \%$ & $79 \%$ & $38 \%$ & $55 \%$ \\
\hline TRP & $40 \%$ & $77 \%$ & $46 \%$ & $67 \%$ & $28 \%$ & $45 \%$ \\
\hline Total & $44 \%$ & $77 \%$ & $49 \%$ & $74 \%$ & $33 \%$ & $50 \%$ \\
\hline
\end{tabular}

Table $7 . \quad$ Relative positive deviance detected per process and across the entire sample (74\%) 
As the observations just outlined are descriptive, we tested their statistical significance. Results from the $\chi^{2}$-test and $w^{2} / \phi^{2}$ computation are summarized in Table 8 (total sample) and Table $9(74 \%)$. The critical $\chi^{2}$-value for one degree of freedom, $\mathrm{df}=1$, and for $\alpha=0.05$ is 3.84 (Rasch et al., 2010). Values above this value are significant (Rasch et al., 2010). Considering both analyses, this applies to the digital nudges Incentive $\left(\chi^{2}=18.50 / 12,47\right)$ and Salience $\left(\chi^{2}=7.51 / 9,34\right)$. The $w^{2} / \phi^{2}$ values can be classified into three categories: small effect with $w^{2}=0.01$, medium effect with $w^{2}=0.09$, and strong effect with $w^{2}=0.25$ (Cohen, 1988; Rasch et al., 2010). Accordingly, Incentive reveals a medium to strong effect $\left(w^{2}=0.12 / 0,11\right)$, whereas Salience reveals a small effect considering the total sample $\left(w^{2}=0.05\right)$ and a medium effect $\left(w^{2}=0.09\right)$ considering the $74 \%$ subset of the total sample. This test corroborates that the results obtained for the digital nudges Incentive as well as Salience are statistically significant, although a high percentage of positive deviance in the control groups was detected.

\begin{tabular}{|c|c|c|c|c|c|c|}
\hline \multicolumn{2}{|c|}{} & Incentive & $\begin{array}{c}\text { Precommit- } \\
\text { ment }\end{array}$ & Salience & Default Setting & $\begin{array}{c}\text { Additional In- } \\
\text { formation }\end{array}$ \\
\hline \multirow{2}{*}{ ADP } & $\boldsymbol{w}^{\mathbf{2}}\left(\boldsymbol{\phi}^{\mathbf{2}}\right)$ & 0.14 & 0.01 & 0.07 & 0.00 & 0.01 \\
& $\chi^{2}$ & 10.90 & 0.52 & 5.36 & 0.28 & 0.52 \\
\hline \multirow{2}{*}{ TRP } & $\boldsymbol{w}^{\mathbf{2}}\left(\boldsymbol{\phi}^{\mathbf{2}}\right)$ & 0.10 & 0.01 & 0.03 & 0.02 & 0.00 \\
& $\chi^{2}$ & 7.21 & 0.61 & 2.29 & 1.35 & 0.13 \\
\hline \hline \multirow{2}{*}{ Total } & $\boldsymbol{w}^{\mathbf{2}}\left(\boldsymbol{\phi}^{\mathbf{2}}\right)$ & 0.12 & 0.01 & 0.05 & 0.01 & 0.00 \\
& $\chi^{2}$ & $18.50^{*}$ & 1.15 & $7.51^{*}$ & 1.30 & 0.59 \\
\hline
\end{tabular}

* statistically significant, $\chi^{2}>3.84$ for $\mathrm{df}=1$ and $\alpha=0.05$

Table $8 . \quad \chi^{2}$-values and $\phi^{2}$-values (total)

\begin{tabular}{|c|c|c|c|c|c|c|}
\hline \multicolumn{2}{|c|}{} & Incentive & $\begin{array}{c}\text { Precommit- } \\
\text { ment }\end{array}$ & Salience & Default Setting & $\begin{array}{c}\text { Additional In- } \\
\text { formation }\end{array}$ \\
\hline \multirow{2}{*}{ ADP } & $\boldsymbol{w}^{\mathbf{2}}\left(\boldsymbol{\phi}^{\mathbf{2}}\right)$ & 0.08 & 0.00 & 0.09 & 0.01 & 0.00 \\
& $\chi^{2}$ & 4.32 & 0.01 & 4.84 & 0.84 & 0.11 \\
\hline \multirow{2}{*}{ TRP } & $\boldsymbol{w}^{\mathbf{2}}\left(\boldsymbol{\phi}^{\mathbf{2}}\right)$ & 0.14 & 0.00 & 0.02 & 0.02 & 0.00 \\
& $\chi^{2}$ & 7.75 & 0.22 & 1.07 & 1.01 & 0.19 \\
\hline \hline \multirow{2}{*}{ Total } & $\boldsymbol{w}^{\mathbf{2}}\left(\boldsymbol{\phi}^{\mathbf{2}}\right)$ & 0.11 & 0.00 & 0.09 & 0.01 & 0.00 \\
& $\chi^{2}$ & $12.47^{*}$ & 0.25 & $9.35^{*}$ & 1.46 & 0.39 \\
\hline
\end{tabular}

* statistically significant, $\chi^{2}>3.84$ for $\mathrm{df}=1$ and $\alpha=0.05$

Table $9 . \quad \chi^{2}$-values and $\phi^{2}$-values (74\% of total with customer experience)

\section{Discussion}

Our research aimed at exploring the potential of digital nudging for light-weight BPI, i.e. whether digital nudging can complement existing BPI methods and serve as foundation for agile process improvement by overcoming the shortcomings of established BPI methods. To achieve this objective, we performed an online experiment based on two customer support processes and five digital nudges. We followed the call of Weinmann et al. (2016) to intensify research on digital nudging and the call of Andrade et al. (2016) to focus on positive deviance. Our findings lead to various implications for researchers and practitioners.

To the best of our knowledge, we were the first to bring digital nudging and business processes together by examining whether digital nudges can entail positive process deviance. From a theoretical perspective, we introduced digital nudges specifically to the BPI context and found that some digital nudges can alter the choice architecture of process participants, in our case employees, and foster positive process deviance. Andrade et al. (2016) already confirmed that process deviance can have positive effects on process performance. Our study yielded similar findings regarding how process participants deviated, e.g. by "calling customer instead of writing an e-mail" or by "asking why a customer wants to delete an account" (Andrade et al., 2016, p. 5). Thus, our work extends existing research on BPI by providing 
insights into an approach based on which the behavior of process participants can be changed without changing the processes themselves. As we will point out in the next section, our results stimulate future research on the usage of digital nudging in other BPM lifecycle phases. For example, Fellmann et al. (2018) call for a "quicker approach for managing and modeling business processes" (p. 21). In our opinion, digital nudging may help extend recommender systems to model business processes more efficiently in the future. Moreover, we see high potential that digital nudging can improve the execution of processes in automated workflow environment based on declarative process models, e.g. by applying different nudges to order possible actions (Vaculin et al., 2013).

From a practical perspective, this is a promising first step to enable agile BPI, which is needed to tackle the characteristics of dynamic business environments. In our experiment, we found that the nudges Incentive and Salience fostered positive process deviance, where Incentive is slightly stronger than Salience. A possible explanation of this behavior is the availability heuristic from behavioral economics. Tversky and Kahnemann (1973) show that the availability of information influences the decision of individuals. By showing the consequences of one's actions, the information is made available and process participants may take them into account more strongly when making decisions. Heath (2012) showed that active attention towards commercials may lead to rational counter-arguing against them. The same could happen in this case such that the more subconscious and less salient Incentive has a stronger effect. This implies that it may be better to use more subconscious digital nudges to get the desired behavior than salient and eye-catching ones. Additionally, our experiment shows that the digital nudge Default Setting has the opposite effect of other nudges. Default settings influence people to stick to a business process as defined upfront (Mirsch et al., 2017). This is based on the psychologic phenomenon of status quo bias, making individuals stick to a decision once it is made, fearing the disadvantages of leaving to outweigh the possible advantages (Kahnemann et al., 1991). The deviation of the group with the digital nudge Default Setting was $10 \%$ lower even than that of the control group. Goldstein et al. (2008) showed that people do not change the default setting, so we would recommend to critically reconsider the usage of this nudge and how to adjust the process design instead to achieve the intended effect. With this, we give a first guidance on the usefulness of different digital nudges for BPI. Additionally, we provide a first start solution in terms of how nudges can be technically integrated in business processes. It is mandatory to understand that it is not possible to nudge process execution paths. By contrast, it is mainly about process activities not the path itself. With that information in mind, BPI initiatives could be more effective, as process managers should understand and analyze where decisions during the process execution are made - in activities, people interact with others or trigger results they have to respond to later. Those activities are the starting points where nudges should be implemented. Further, digital nudging can be integrated in the improvement phase of the BPM lifecycle and serve as an agile and light-weight approach to quickly evaluate the effects of improvement ideas and shorten the time until improvements become effective. This is similar to A/B testing (Satyal et al., 2019) where different variants of an application are tested in live experiments (Tamburrelli and Margara, 2014). In fact, organizations may not have enough resources to implement all potentially valuable process improvement ideas through projects such that digital nudging offers a favorable cost-value ratio.

\section{Conclusion}

Over the last decades, a mature BPI toolbox has emerged (Dumas et al., 2018). Most related methods, however, are complex (Yusof and Aspinwall, 2000), costly, and time-consuming (van der Aalst et al., 2016), characteristics that do not fit volatile, uncertain, complex, and ambiguous business environments. Based on an online experiment, we found that digital nudging promises to be a useful foundation for agile BPI, mitigating the weaknesses of other BPI methods (Mirsch et al., 2017). By stimulating process participants to positively deviate from predefined business processes, digital nudging complements extant methods by facilitating the fast validation of improvement ideas (in the sense of A/B testing) and by reducing improvement latency (the time between the initiation of a BPI initiative and the adoption of the envisioned changes). Our study offers a differentiated view on digital nudging in the BPI context. Most investigated nudges led to changed behavior. Some of them (i.e. Incentive and Salience) positively influenced process participants, while others had no or even negative effects. 
Like in most experiments, our results must be interpreted with respect to some limitations. First, our results are based on an online experiment and do not reflect the behavior of people in naturalistic settings. In the experiment, participants performed the processes once. In real work environments, they would be more familiar with the processes in focus and execute them repeatedly. Additionally, they would better know about the consequences with respect to additional costs and time savings before deviating from the standard process. Therefore, the question arises whether the participants would have decided differently in view of such information. Furthermore, the processes were static, and we do not know how customers or process participants would have reacted on how the participants contacted them. The second limitation is that we did not test the effects of the digital nudges on participants with different characteristics such as personality types, gender, or age. We also considered the effects of digital nudges at one point in time. However, the effectiveness of digital nudges could vary over time. Finally, it should be considered that digital nudges cannot be implemented in all processes but are limited to those conducted in automated execution environments.

The results of the experiment and the outlined limitations offer opportunities for future research. First, it would be interesting to investigate the effects of digital nudges in naturalistic settings via field experiments. Moreover, controlling for process participants' personality types could provide insights into the need for personalized nudges in digital work environments. Apart from that, the literature lists plenty of other nudges whose effectiveness in BPM contexts should be examined as well. Researchers should also consider whether the effectiveness of digital nudges depends on the characteristics of business processes and whether the combination of digital nudges would intensify or weaken their effect (correlation among digital nudges). Additionally, more confirmatory studies could use our results for theory building and developing nudging-creation-methods like the DINU (digital nudging process model) model provided by Meske and Potthoff (2015). Finally, a taxonomy of digital nudges including their affordances for different phases of the BPM lifecycle would be beneficial for future sense-making and design-led research - not only in BPM, but also in general information systems contexts. 


\section{References}

Al-Mashari, M., Z. Irani and M. Zairi (2001). "Business process reengineering: a survey of international experience" Business Process Management Journal 7 (5), 437-455.

Alter, S. (2014). "Theory of Workarounds" Communications of the Association for Information Systems 34, 1041-1066.

Andersson, Ö. (2012). Experiment! Planning, implementing, and interpreting. 1st edition. Chichester: Wiley.

Andrade, E., H. van der Aa, H. Leopold, S. Alter and H. A. Reijers (2016). "Factors Leading to Business Process Noncompliance and its Positive and Negative Effects: Empirical Insights from a Case Study". In Proceedings of the 22nd Americas Conference Information Systems, pp. 640-649. San Diego.

Ashraf, N., D. S. Karlan and W. Yin (2006). "Tying Odysseus to the mast: Evidence from a com-mitment savings product in the Philippines" The Quarterly Journal of Economics 121 (2), 635-672.

Behrend, T. S., D. J. Sharek, A. W. Meade and E. N. Wiebe (2011). "The viability of crowdsourcing for survey research" Behavior research methods 43 (3), 800-813.

Bennett, N. and J. Lemoine (2014). "What a Difference a Word Makes: Understanding Threats to Performance in a VUCA World" Business Horizons 57 (3), 311-317.

Bond, R. M., C. J. Fariss, J. J. Jones, A. D. I. Kramer, C. Marlow, J. E. Settle and J. H. Fowler (2012). "A 61-million-person experiment in social influence and political mobilization" Nature 489 (7415), 295-298.

Brady, F. (2003). "Working around Security: Issue of Implementation and Distance". In Proceedings of the 5th International Conference on Information Technology in Regional Areas, pp. 253-259. Caloundra, Queensland.

Buhl, H. U., M. Röglinger, S. Stöckl and K. S. Braunwarth (2011). "Value Orientation in Process Management" Business \& Information Systems Engineering 3 (3), 163-172.

Buhrmester, M., T. Kwang and S. D. Gosling (2011). “Amazon"s Mechanical Turk: A New Source of Inexpensive, Yet High-Quality, Data?" Perspectives on psychological science: a journal of the Association for Psychological Science 6 (1), 3-5.

Chang, H. "S.", C. Huh and M. J. Lee (2016). "Would an Energy Conservation Nudge in Hotels Encourage Hotel Guests to Conserve?" Cornell Hospitality Quarterly 57 (2), 172-183.

Chen, H. and R. Taylor (2009). "Exploring the impact of lean management on innovation capability". In PICMET 2009, pp. 826-834.

Chetty, R., A. Looney and K. Kroft (2009). "Salience and Taxation: Theory and Evidence" American Economic Review 99 (4), 1145-1177.

Cohen, J. (1960). “A Coefficient of Agreement for Nominal Scales" Educational and Psychological Measurement 20 (1), 37-46.

Cohen, J. (1988). Statistical power analysis for the behavioral sciences. 2. ed. Hillsdale, NJ: Erl-baum.

Cohn, K. H. (2009). "Changing Physician Behavior Through Involvement and Collaboration” Jour-nal of Healthcare Management 54 (2), 80-86.

Croson, R. and J. Shang (2008). "The impact of downward social information on contribution decisions" Experimental Economics 11 (3), 221-233. 
de Bruin T. and M. Rosemann (2007). "Using the Delphi Technique to Identify BPM Capability Areas". In Proceedings of the 18th Australasian Conference on Information Systems, pp. 643-653. Too-woomba.

Demarque, C., L. Charalambides, D. J. Hilton and L. Waroquier (2015). "Nudging sustainable consumption: The use of descriptive norms to promote a minority behavior in a realistic online shopping environment" Journal of Environmental Psychology 43, 166-174.

Depaire, B., J. Swinnen, M. Jans and K. Vanhoof (2013). "A Process Deviation Analysis Framework”. In M. La Rosa and P. Soffer (eds.) Business process management workshops. BPM 2012 international workshops, Tallinn, Estonia, September 3, 2012, revised papers, pp. 701-706. Berlin, New York: Springer.

Dolan, P., M. Hallsworth, D. Halpern, D. King, R. Metcalfe and I. Vlaev (2012). "Influencing be-haviour: The mindspace way” Journal of Economic Psychology 33 (1), 264-277.

Dumas, M., M. La Rosa, J. Mendling and H. A. Reijers (2018). Fundamentals of Business Process Management. 2nd ed. 2018. Berlin, Heidelberg: Springer Berlin Heidelberg.

Dumas, M. and F. M. Maggi (2015). "Enabling Process Innovation via Deviance Mining and Predictive Monitoring”. In J. Vom Brocke and T. Schmiedel (eds.) BPM - Driving Innovation in a Digital World. 1st Edition, pp. 145-154. Cham: Springer.

Evans, J. S. B. T. (2008). "Dual-processing accounts of reasoning, judgment, and social cognition" Annual review of psychology 59, 255-278.

Fellmann, M., D. Metzger, S. Jannaber, N. Zarvic and O. Thomas (2018). "Process Modeling Rec-ommender Systems” Business \& Information Systems Engineering 60 (1), 21-38.

Ferraris, A., F. Monge and J. Mueller (2018). "Ambidextrous IT capabilities and business process performance: an empirical analysis" Business Process Management Journal 24 (5), 1077-1090.

Galperin, B. L. (2012). "Exploring the Nomological Network of Workplace Deviance: Developing and Validating a Measure of Constructive Deviance" Journal of Applied Social Psychology 42 (12), $2988-3025$.

Gimpel, H., S. Hosseini, R. Huber, L. Probst, M. Röglinger and U. Faisst (2018). "Structuring Digi-tal Transformation: A Framework of Action Fields and its Application at ZEISS" Journal of In-formation Technology Theory and Application 19 (1), 31-54.

Goldin, J. (2015). "Which Way to Nudge? Uncovering Preferences in the Behavioral Age" Yale Law Journal 125 (1), 226-270.

Goldstein, D. G., M. Heitmann and E. J. Johnson (2008). "Nudge Your Customers Toward Better Choices" Harvard Business Review 86, 99-106.

Gregor, S. and B. Lee-Archer (2016). "The digital nudge in social security administration" International Social Security Review 69 (3-4), 63-83.

Hallgren, K. A. (2012). “Computing Inter-Rater Reliability for Observational Data: An Overview and Tutorial” Tutorials in Quantitative Methods for Psychology 8 (1), 23-34.

Halpern, S. D., P. A. Ubel and D. A. Asch (2007). "Harnessing the Power of Default Options to Improve Health Care" New England Journal of Medicine 357 (13), 1340-1344.

Hansen, P. G. and A. M. Jespersen (2013). "Nudge and the Manipulation of Choice" European Journal of Risk Regulation 4 (01), 3-28.

Harmon, P. (2004). "Evaluating an Organization's Business Process Maturity" Business Process Trends 2 (3). 
Harmon, P. (2018). The State of Business Process Management 2018. URL:

https://www.redhat.com/cms/managed-files/mi-bptrends-state-of-bpm-2018-survey-analyst-paper201803-en.pdf (visited on 07/09/2019).

Harmon, P. (2019). Business Process Change, 4th Edition. 4th edition: Morgan Kaufmann.

Heath, R. (2012). Seducing the subconscious. The psychology of emotional influence in advertising. Chichester, West Sussex, Hoboken, NJ: Wiley.

Houde, S., A. Todd, A. Sudarshan and K. Carrie Armel (2013). "Real-time Feedback and Electricity Consumption: A Field Experiment Assessing the Potential for Savings and Persistence" The Energy Journal 34 (1), 1-16.

Hummel, D. and A. Maedche (2019). "How effective is nudging? A quantitative review on the effect sizes and limits of empirical nudging studies" Journal of Behavioral and Experimental Econom-ics $80,47-58$.

John, P., S. Cotterill, A. Moseley, L. Richardson, G. Smith, G. Stoker and C. Wales (2013). Nudge, nudge, think, think. Experimenting with ways to change civic behaviour. Revised paperback edition. London, New Delhi, New York, Sydney: Bloomsbury.

Kahneman, D., J. L. Knetsch and Richard H. Thaler (1991). "Anomalies: The Endowment Effect, Loss Aversion, and Status Quo Bias” Journal of Economic Perspectives (5), 193-206.

Kerpedzhiev, G., U. König, M. Röglinger and M. Rosemann (2017). Business Process Management in the Digital Age. Digitalization is a game-changer for BPM. BP Trends Article. URL: https://www.fim-rc.de/Paperbibliothek/Veroeffentlicht/693/wi-693.pdf (visited on 07/09/2019).

Khern-am-nuai, W., W. Yang and N. Li (2017). "Using Context-Based Password Strength Meter to Nudge Users" Password Generating Behavior: A Randomized Experiment". In: Proceedings of the 50th Hawaii International Conference on System Sciences: Hawaii International Conference on System Sciences.

Kim, Y. M., M. Heerey and A. Kols (2008). "Factors that enable nurse-patient communication in a family planning context: a positive deviance study" International journal of nursing studies 45 (10), 1411-1421.

Koehler, J. (2018). "Business Process Innovation with Artificial Intelligence: Levering Benefits and Controlling Operational Risks” European Business \& Management 4 (2), 55.

Kohlbacher, M. and H. A. Reijers (2013). "The effects of process-oriented organizational design on firm performance” Business Process Management Journal 19 (2), 245-262.

König, U. M., A. Linhart and M. Röglinger (2018). "Why do business processes deviate? Results from a Delphi study" Business Research 5 (1), 87.

Krippendorff, K. (2004). Content analysis. An introduction to its methodology. 2nd ed. Thousand Oaks Calif.: Sage.

Landis, J. R. and G. G. Koch (1977). "The Measurement of Observer Agreement for Categorical Data" Biometrics 33 (1), 159-174.

Lehnert, M., A. Linhart, J. Manderscheid and M. Svechla (2016). "V3PM: A Decision Support Tool for Value-based Process Project Portfolio Management". In Proceedings of the 24th European Conference on Informatin Systems (ECIS), pp. 1-10.

Light, R. J. (1971). "Measures of response agreement for qualitative data: Some generalizations and alternatives" Psychological Bulletin 76 (5), 365-377.

Mann, T. and A. Ward (2007). "Attention, Self-Control, and Health Behaviors" Current Directions in Psychological Science 16 (5), 280-283. 
Martins, P. V. and M. Zacarias (2017). “An Agile Business Process Improvement Methodology” Procedia Computer Science 121, 129-136.

Mendenhall, W. and R. J. Beaver (2013). Introduction to probability and statistics. 14th ed. Boston, MA: CL-Wadsworth.

Mertens, W. and J. Recker (2017). "Positive Deviance and Leadership: An Exploratory Field Study". In: Proceedings of the 50th Hawaii International Conference on System Sciences: Hawaii International Conference on System Sciences.

Mertens, W., J. Recker, T.-F. Kummer, T. Kohlborn and S. Viaene (2016). "Constructive deviance as a driver for performance in retail" Journal of Retailing and Consumer Services 30, 193-203.

Meske, C. and T. Potthoff (2017). "The DINU-Model - A Process Model for the Design of Nudges". In Proceedings of the 25th European Conference on Information Systems, pp. 2587-2597.

Mirsch, T., C. Lehrer and R. Jung (2017). "Digital Nudging: Altering User Behavior in Digital Environments". In Proceedings of the 13th International Conference on Wirtschaftsinformatik, pp. 634-648. St. Gallen.

Noar, S. M., M. G. Hall, D. B. Francis, K. M. Ribisl, J. K. Pepper and N. T. Brewer (2015). "Picto-rial cigarette pack warnings: a meta-analysis of experimental studies" Tobacco control 25 (3), 341354.

Pahuja, A. and C.-H. Tan (2017). "Breaking the Stereotypes: Digital Nudge to Attenuate Racial Stereotyping in the Sharing Economy". In Proceedings of the 38th International Conference on Information Systems. Seoul.

Pascale, R., J. Sternin and M. Sternin (2010). The Power of Positive Deviance. How Unlikely Innovators Solve the World"s Toughest Problems. Boston: Harvard Business Review Press.

Peer, E., J. Vosgerau and A. Acquisti (2014). "Reputation as a sufficient condition for data quality on Amazon Mechanical Turk" Behavior research methods 46 (4), 1023-1031.

Rasch, B., M. Friese, W. Hofmann and E. Naumann (2010). Quantitative Methoden. 3., erw. Aufl. Berlin, Heidelberg: Springer.

Reijers, H. A. and L. S. Mansar (2005). "Best practices in business process redesign: an overview and qualitative evaluation of successful redesign heuristics" The International Journal of Man-agement Science 33 (4), 283-306.

Satyal, S., I. Weber, H.-y. Paik, C. Di Ciccio and J. Mendling (2019). "Business process improve-ment with the AB-BPM methodology" Information Systems 84, 283-298.

Schneider, C., M. Weinmann and J. Vom Brocke (2018). "Digital Nudging: Guiding Online User Choices through Interface Design" Communications of the ACM 61 (7), 67-73.

Schneider, D., S. Lins, T. Grupp, A. Benlian and A. Sunyaev (2017). "Nudging Users Into Online Verification: The Case of Carsharing Platforms" ICIS 2017 Proceedings 11.

Seidman, W. and M. McCauley (2008). "Positive Deviants Rule!” Cutter IT Journal 21 (7), 16-20.

Spreitzer, G. M. and S. Sonenshein (2004). "Toward the Construct Definition of Positive Deviance" American Behavioral Scientist 47 (6), 828-847.

Tamburrelli, G. and A. Margara (2014). "Towards Automated A/B Testing”. In C. Le Goues and S. Yoo (eds.) Search-based software engineering. 6th International Symposium, SSBSE 2014, Fortaleza, Brazil, August 26-29, 2014. Proceedings, pp. 184-198. Cham: Springer.

Thaler, R. H. and C. R. Sunstein (2008). Nudge. Improving decisions about health, wealth, and happiness. Rev. and expanded ed. New York, NY: Penguin. 
Tversky, A. and D. Kahneman (1973). "Availability: A heuristic for judging frequency and probability” Cognitive Psychology (5), 207-232.

Tversky, A. and D. Kahnemann (1974). "Judgment under Uncertainty: Heuristics and Biases” Science 185 (4157), 1124-1131.

Vaculin, R., R. Hull, M. Vukovic, T. Heath, N. Mills and Y. Sun (2013). "Supporting Collaborative Decision Processes". In: IEEE International Conference on Services Computing (SCC), 2013. June 28, 2013 - July 3, 2013, Santa Clara, California. Piscataway, NJ: IEEE, pp. 651-658.

Vadera, A. K., M. G. Pratt and P. Mishra (2013). "Constructive Deviance in Organizations" Journal of Management 39 (5), 1221-1276.

Vakola, M. and Y. Rezgui (2000). "Critique of existing business process re-engineering methodologies” Business Process Management Journal 6 (3), 238-250.

van der Aalst, W. M. P., M. La Rosa and F. M. Santoro (2016). "Business Process Management" Business \& Information Systems Engineering 58 (1), 1-6.

Walton, M. (1988). The Deming Management Method. New York, N.Y.: Putnam Publ. Co.

Weinmann, M., C. Schneider and J. Vom Brocke (2016). "Digital Nudging” Business \& Information Systems Engineering 58 (6), 433-436.

Yusof, S."R. M. and E. Aspinwall (2000). "Total quality management implementation frameworks: comparison and review" Total Quality Management 11 (3), 281-294. 